\title{
A Historical Review of Echocardiographic Detection of Pericardial Effusion
}

\author{
Sonia Chang* and John K. GHAnG**
}

\section{EARLY WORK :}

Great scientific events happen quietly, often without recognition by one's contemporary collegues. It is only with a historical perspective that one can see how a new technique or way of thinking could open a new era of diagnostic expertise. Such was the case of echocardiography and the noninvasive diagnosis of pericardial effusion.

The first echocardiograms of pericardial effusion were published by Dr. Inge Edler and Dr. C. H. Hertz of Swedan in 1954. ${ }^{11,2)}$ A representative echocardiogram is shown in Figure 1. The echogram was recorded on an industrial ultrasound reflectoscope used for nondestructive flaw detection in solid metals. In later studies, an electrocardiogram was reflected from the electrocardiograph to the ultrasonoscope's cathode ray tube via a mirror. Continuous film recording was achieved with a camera mounted in front of the oscilloscope. The origins of reflected sound from different parts of the heart were experimentally identified with preparations of isolated calf and cadaver hearts. ${ }^{2,3)}$ Echocardiographic inscriptions of the presumed anterior and posterior ventricular wall movements from living patients were correlated with their roentgenograms. ${ }^{3)}$

The potential clinical use of reflected ultrasound detection of pericardial effusion behind the living heart did not appear in the American literature until 11 years later in 1965.4) Feigenbaum and associates had recorded systolic movement of the canine posterior left ventricular wall on an ultrasonoscope borrowed from the Neurology Department at Indiana University Medical Center. Small quantities of saline were injected into the pericardial sac via an indwelling catheter while continuously monitoring echographic posterior wall motion. Appearance of another, immobile echo indicated separation of the posterior wall from the pericardium. The saline was represented by the echo-free space between the echoes reflected from the mobile posterior ventricular wall and the immobile pericardium. Representative echographic patterns of motion are shown in Figure 2.

* Allied Health Professional: Consultant in Echocardiography, Riverside Hospital, Toledo, Ohio.

** Director, Echocardiographic Laboratory, Riverside Hospital, Toledo, Ohio

Received for publication December 10, 1980. 


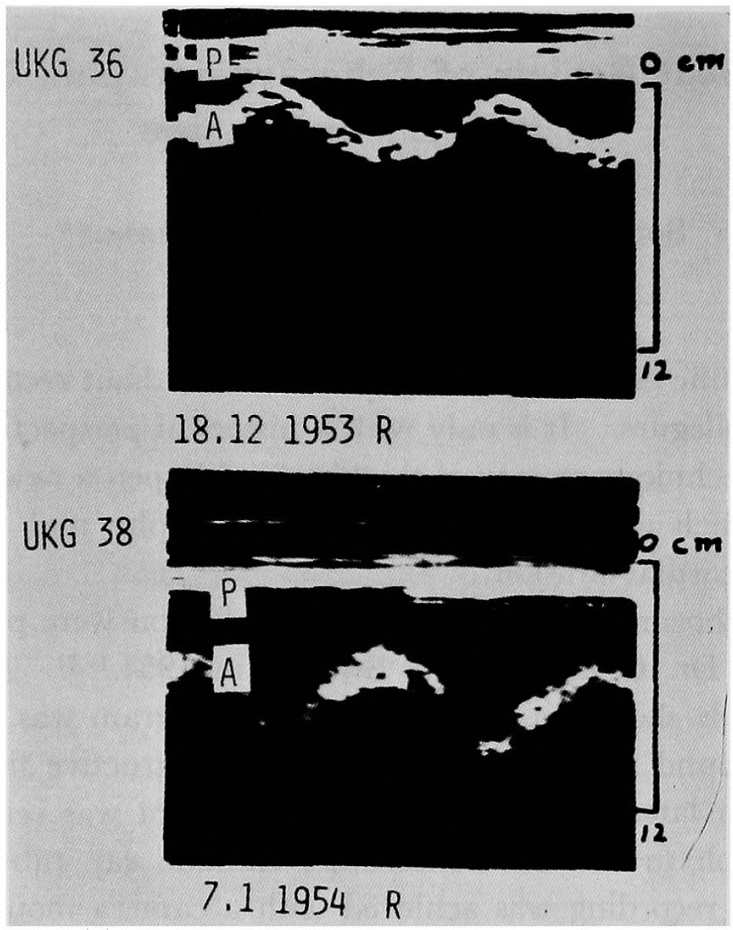

Fig. 1. One of the first echocardiograms of progressive accumulation of pericardial effusion. Tracing represented fluid separating anterior right ventricular wall from inner chest wall. (Reprinted with permission: Edler I, Hertz CH.: The use of ultrasonic reflectoscope for the continuous recording of the movements of heart walls. Kugliga Fysiografiska Sällskapets i Lund förhandlingar. Bd. 24. Nr. 5, March 10, 1954).
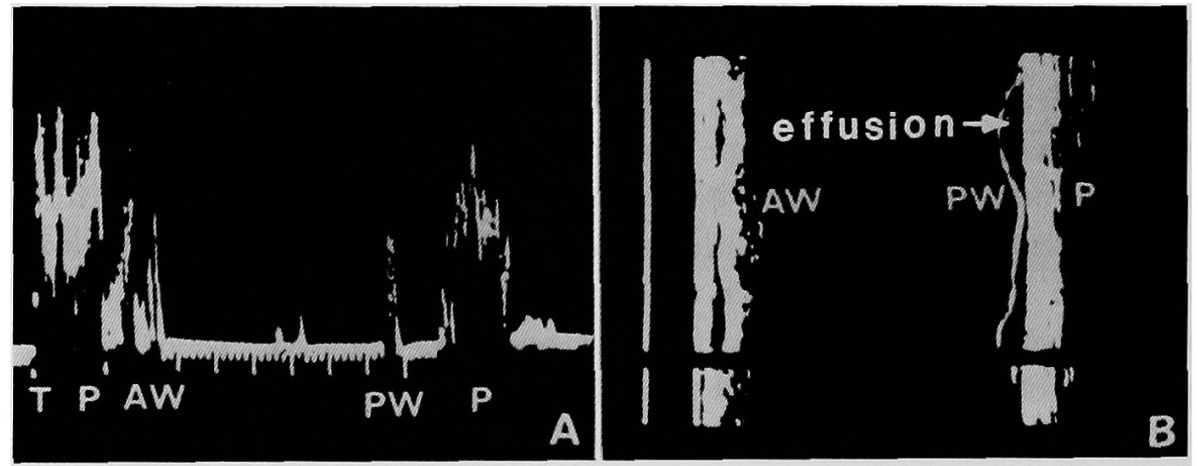

Fig. 2. Echocardiograms from a patient with anteriorly and posteriorly distributed pericardial effusion. (Left panel): A-mode echogram from patient. Cardiac movement could not be appreciated on photograph. (Right panel): M-mode echogram from same patient. Space separating posterior wall echo (PW) from pericardium (P) represented small quantity of pericardial effusion. $\mathrm{T}=$ transducer; $\mathrm{AW}=$ anterior wall. (Reprinted with permission: Feigenbaum H, Zaky A, Waldhausen JA: Use of ultrasound in the diagnosis of pericardial cffusion. Ann Intern Med 65(3): 443-452, 1966, Fig. 4, p. 447). 
Aspiration of the saline from the pericardial sac allowed the immobile echo (pericardium) to move closer to and finally fuse with the echo which moved with cardiac systole (posterior wall). These investigators predicted that "... this technique (reflected ultrasound) promises to be highly sensitive as well as reliable in detecting pericardial effusion." 4$)$

These preliminary studies ${ }^{4}$ were followed by confirmation of their clinical usefulness. ${ }^{51,6)}$ The presence of pericardial effusion was proven by pericardiocentesis, surgery, autopsy, cardiac catheterization, angiography, intravenous carbon dioxide radiographic techniques or a chest scan using intravenous radioactive albumin.

\section{DEVELOPMENT OF EXAMINATION TECHNIQUES:}

Following Feigenbaum's first description of techniques for echocardiographic examination for pericardial effusion, ${ }^{5)}$ use of this method rapidly gained popularity. The equipment was portable to the bedside of critically ill patients and without $\mathrm{X}$-ray exposure to either the patient or the examiner. The patient could be examined in a supine or sitting position and usage of physician time was minimal_- " five minutes." ")

As of 1968, the echographic representation of pericardial effusion remained unchanged from Dr. Edler's and Dr. Feigenbaum's early work. The technique of examination was, howcver, becoming less simplistic and for the first time authors indicated that the technologist ${ }^{10), 11}$ and physician ${ }^{13}$ must be well trained to obtain diagnostic echograms and interpret them correctly.

Echocardiographic landmarks had not been established. Reflected echoes from the mitral annulus and ventricular septum had motion patterns similar to those reflected from the anterior and posterior ventricular walls. Investigators described potential sources of misinterpretation due to "error in technic ", ${ }^{7}$ presence of pleural effusion, ${ }^{8}$ ) and intrapericardial thrombus, ${ }^{10)}$ whose echograms resembled pericardial effusion. The quantity of separation between the visceral and partial pericardiums, as an estimation of pericardial fluid volume, was not correlating well with estimates of volume derived by other methods.7,91,10) However, the technique was found to be sensitive for detection of at least 40 or $50 \mathrm{cc}$ of intrapericardial fluid. ${ }^{11,12)}$

Evidence of experimentation with the transducer's position and angulation, and altered instrument settings appeared suddenly.17),18) Landmarks were definitively established. One had to simultaneously record the left side of the interventricular septum and the endocardial and epicardialpericardial interfaces of the posterior left ventricular wall at mid-ventricular level. Angulation of the transducer toward the patient's midline was (and is) 
discouraged during examination of the left ventricle with M-mode echocardiography.

These technical requirements served to eliminate many potential false positive effusions due to unwitting recording of the mitral annulus or posterior mediastinal structures. ${ }^{19)}$ While recording, damping (pulse voltage) was changed from maximum to minimum to isolate pericardial echoes from the ventricular myocardium. Echo-free space between moving and nonmoving structures represented pericardial effusion (Figure 3).

Patients were altered from a supine position to a partial left lateral decubitus position. The transducer occupied other intercostal spaces and it was no longer held stationary during recording. Optimal mid-left ventricular studies were obtained by angling the transducer from the aorta toward the apex or scanning. ${ }^{20)-22}$ Accidental slowing of the paper recording speed during a routine scan produced compressed scans which optically improved

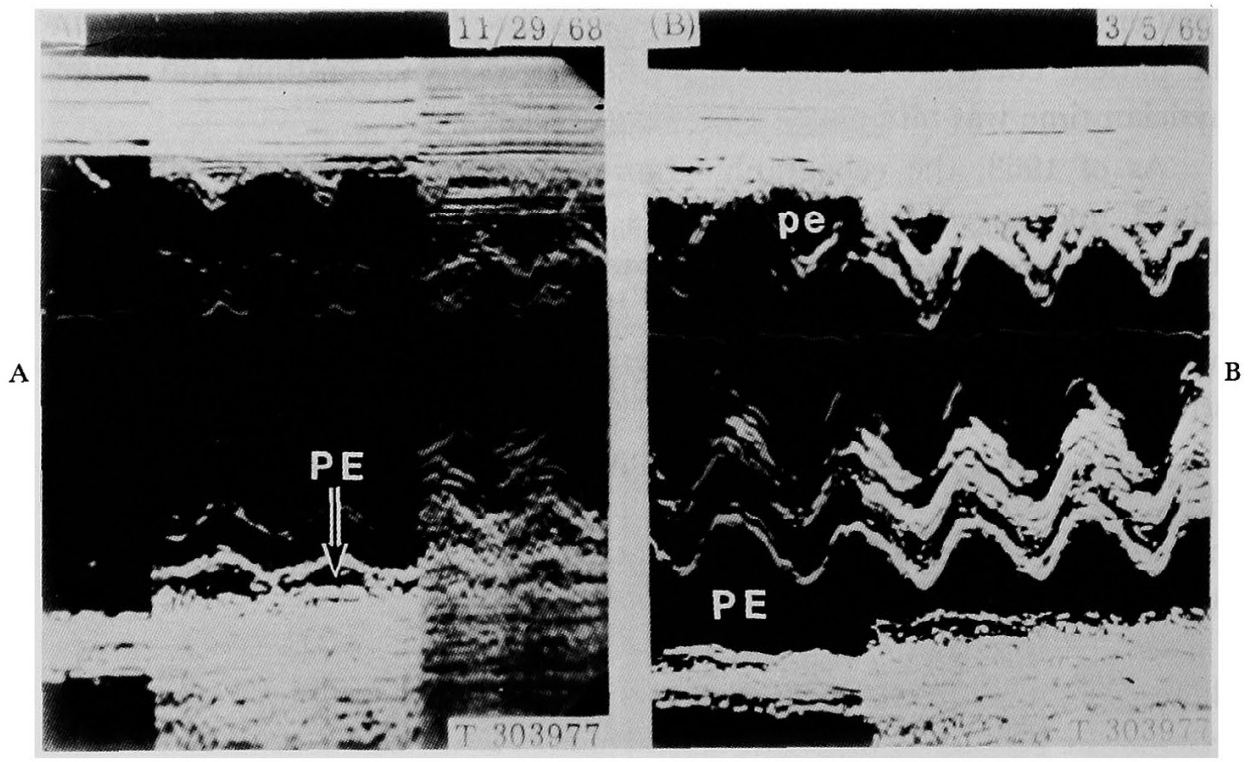

Fig. 3. Echocardiogram from patient with (A) small pericardial effusion and (B) marked increase in quantity of fluid seen three months later. A: Echoes reflected from interventricular septum were required in routine study of left ventricle and evaluation for pericardial effusion. Signal attenuation (damping) was changed rapidly from maximum to minimum during photographic recording. Purpose of damping was threefold: to isolate pericardium; then add echoes from endocardial and epicardial interfaces; then fill in myocardial tissue. B: A large quantity of pericardial effusion allowed heart to oscillate freely. Only anterior and posterior wall and some portion of posterior papillary muscle were evident. All structures moved in unison. (Reprinted with permission: Feigenbaum H: Echocardiographic diagnosis of pericardial effusion. Am J Cardiol 26: 475-479, 1970). 
our appreciation of the spatial distribution of posterior pericardial effusion. ${ }^{18)}$ Concurrent presence of pleural effusion suspended the pericardium between the two fluids (Figure 4).

\section{CLINICAL USE AND INTERPRETATION:}

Unrestricted cardiac movement within extremely large pericardial effusions was regularly described. ${ }^{10), 33), 34)}$ Using techniques of M-mode scanning, ${ }^{18,{ }^{211}}$ LeMire, ${ }^{34)}$ Greene, ${ }^{35)}$ Martin, ${ }^{36)}$ and their respective associates demonstrated echographic evidence of pericardial effusion located behind the left atrium (Figure 5). Effusions in this area were previously thought to be limited to pleural effusion. ${ }^{201,37,38)}$ This fluid accummulation was possible through an anatomical communication between the pericardial cavity and the oblique pericardial sinus. ${ }^{38), 391}$

In a few laboratories, the echogram was used to assist localization and distribution of pericardial fluid prior to pericardiocentesis, thus eliminating " ... the necessity for stand-by $X$-ray equipment or moving the patient to the $X$-ray department." 10$)$ Echocardiography was incorporated into the actual procedure of pericardiocentesis by Goldberg and Pollack. ${ }^{15,16)}$ While monitoring echographic displays of pericardial effusion, an aspiration needle was positioned through a central lumen in the transducer. The relationship between the tip of the needle and the cardiac epicardium could be monitored continuously during aspiration of effusion from the supine or sitting patient.

The sensitivity and specificity of echocardiographic diagnosis of pericardial effusion was re-assessed by Horowitz and associates. ${ }^{23)}$ These investigators re-affirmed that " . . the classic pattern of an echo-free space persisting throughout the cardiac cycle between the epicardium and a poorly moving or flat pericardium relative to the epicardium was always associated with more than $15 \mathrm{ml}$ of pericardial fluid." "23) Further attempts to quantitate pericardial fluid volume have not progressed beyond designations of small, moderate and large. ${ }^{32), 42) ~ " T h e ~}$ existance of a large anterior separation was associated with a moderate to large pericardial effusion only in the presence of a large posterior echo-free space." ${ }^{23)}$ However, large anterior separations between the right ventricular wall and chest wall, in the absence of posterior effusions were later shown to be associated with intrapcricardial cysts. ${ }^{24}$ This kind of echographic presentation was also consistent with a fluid-tissue tumor, ${ }^{25)-291,51)}$ epicardial fat or loculated pericardial fluid. ${ }^{29)}$

In 1969, Feigenbaum considered the potential for characterization of the pericardial effusion when he indicated that "any particulate matter, including red blood cells, will produce echoes if the sensitivity is high enough." ${ }^{13)}$ When the sensitivity is adequate to visualize the ventricular myocardium, homogeneous 


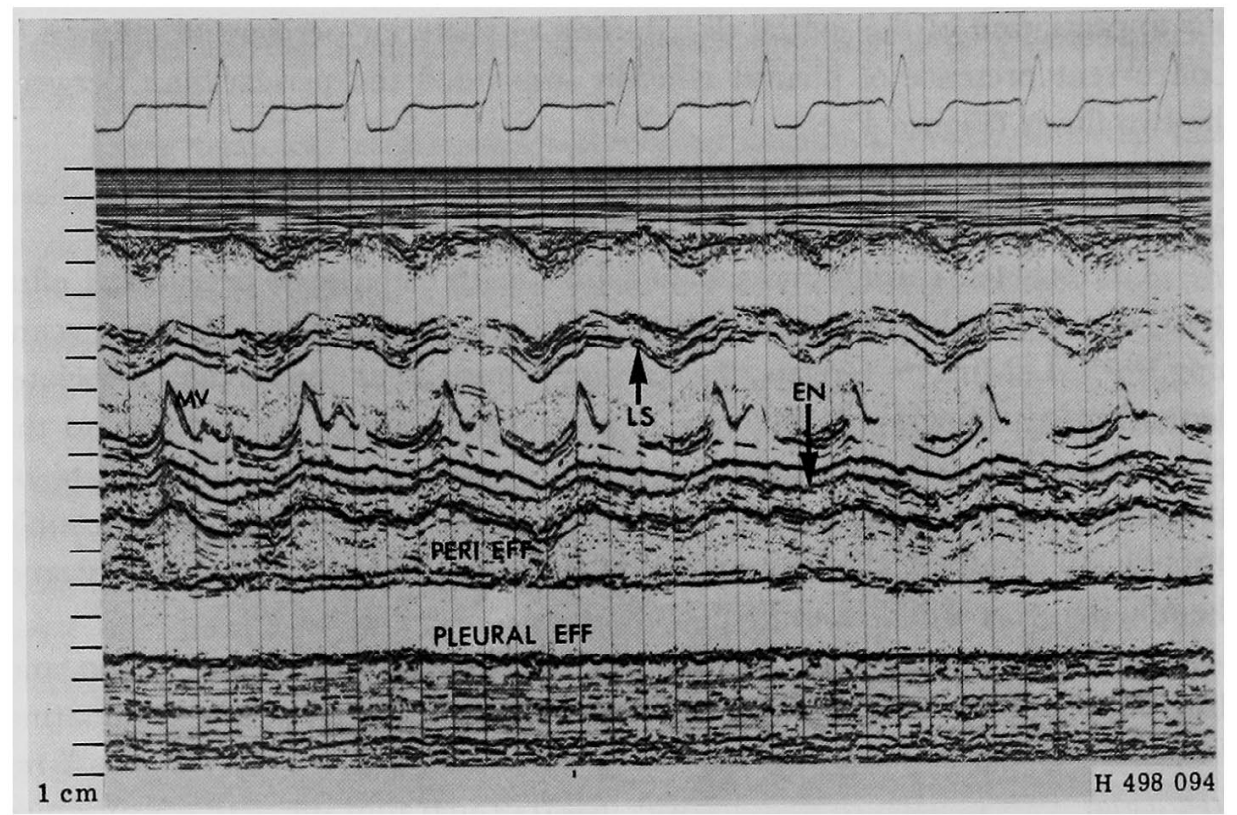

Fig. 4. Patient with pericardial and pleural effusion showing parietal pericardium suspended between both fluid mediums. EN=endocardial surface of posterior left ventricular wall; $L S=$ left septum; $M V=$ mitral valve motion; PERI EFF = pericardial effusion. (Reprinted with permission: Chang S: M-MODE ECHOCARDIOGRAPHIG TECHNIQUES AND PATTERN RECOGNITION. Lea \& Febiger, Philadelphia, 1976).

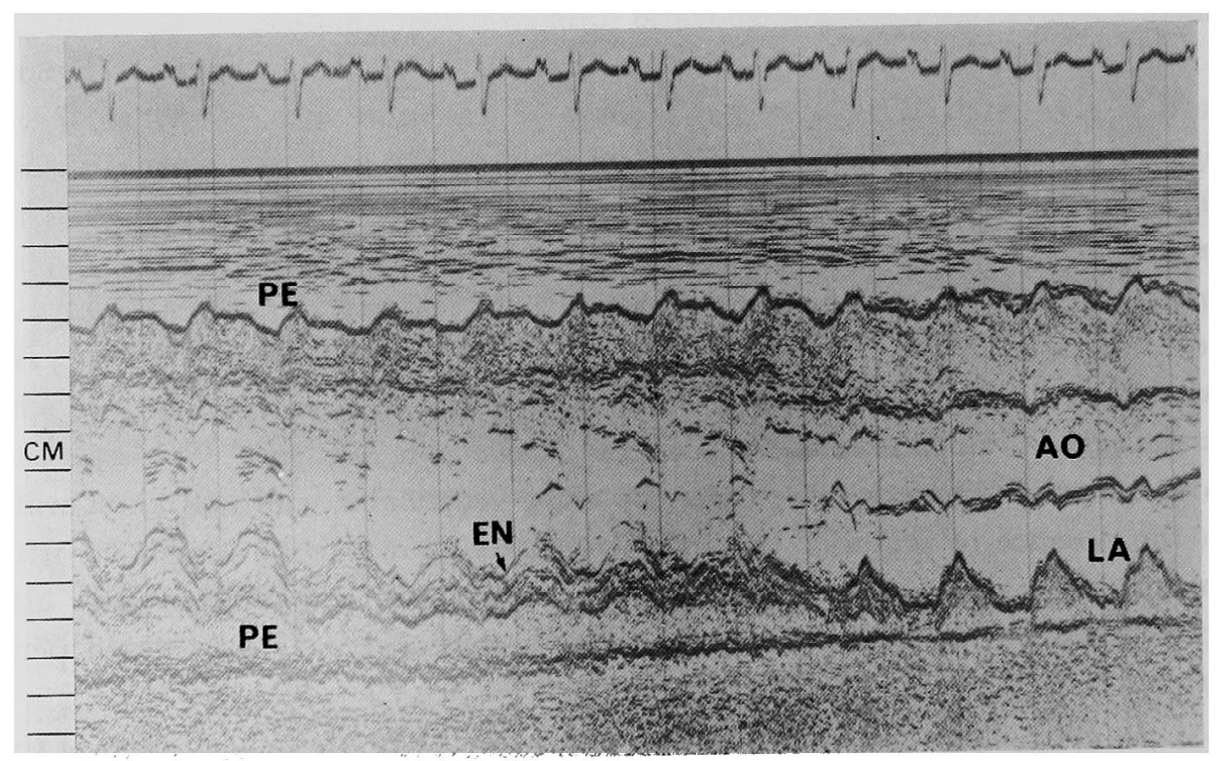

Fig. 5. A 76-year-old male with large pericardial effusion extending into oblique pericardial sinus located behind posterior left atrial wall. $P E=$ pericardial effusion; $\mathrm{EN}=$ endocardial surface of posterior left ventricular wall; $\mathrm{AO}=$ aorta $; \mathrm{LA}=$ left atrium. 
fluid remains relatively echo-free. Semisolid, or liquid fluid with free-floating particulate inclusions continuously prove to be echo-reflective, at least as much or more so than the ventricular myocardium. ${ }^{18), 30)-32,51)}$ Of more importance has been the increased echo-reflectiveness of the visceral and parietal pericardiums and unity of movement in the presence of fibro-adhesive disease. ${ }^{23), 51)}$ Figure 6 demonstrated thickening of the pericardium and probably adhesion between the visceral and parietal pericardiums. Figure 7 showed increased echo-reflectiveness from both the visceral and parietal pericardiums. Fibro-adhesive pericardial disease was subsequently proven with surgery.

Reports of unsuspected pericardial effusion increased as echocardiographic skills and recording equipment improved. Riba and Morganroth ${ }^{40)}$ found echographic evidence of pericardial effusion in 189 of 1,225 consecutive patients. Analysis was applied to 111 of these patients in whom pericardial effusion was clinically unsuspected in 68 or $61 \%$. Sixty percent $(41 / 68)$ of these patients had underlying organic heart disease. These clinically un-

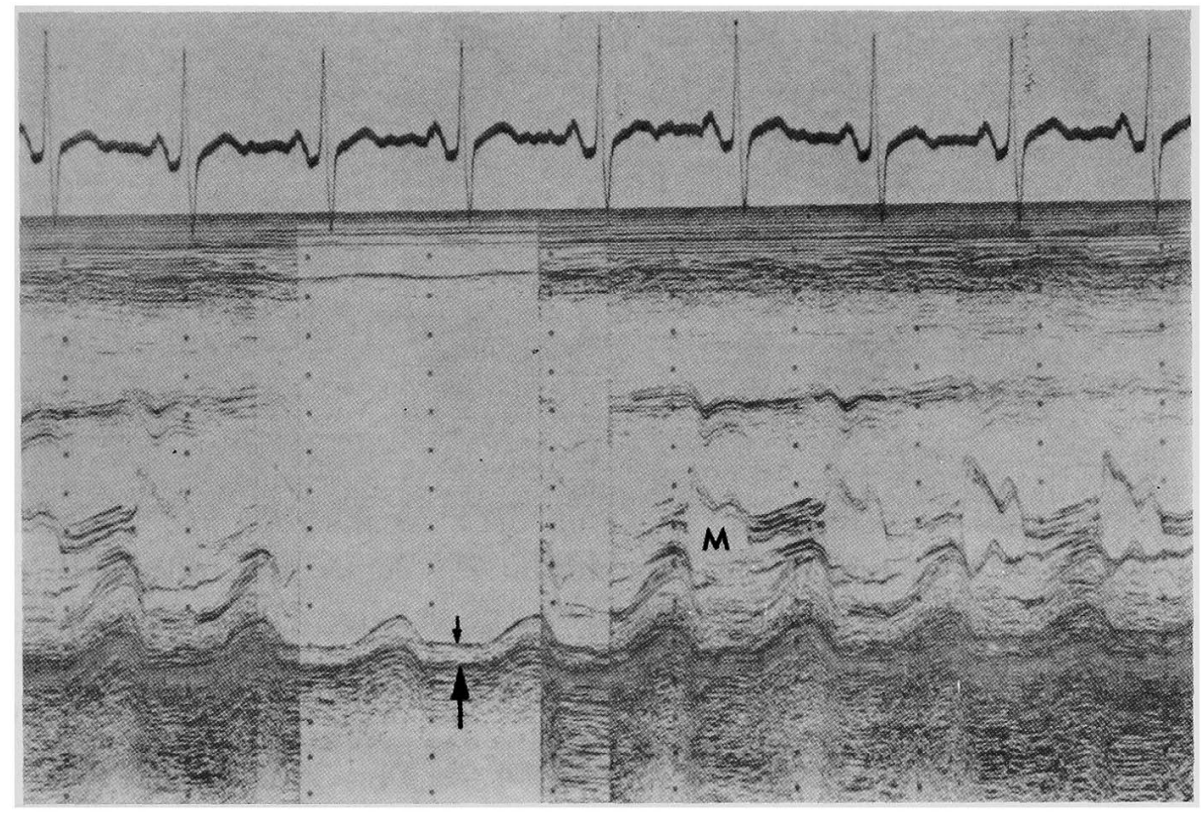

Fig. 6. A 30-year-old male; 8 days after removal of two mediastinal abscesses secondary to dental abscess. There was echographic evidence of a thickened pericardium (arrows) when echoes were attenuated. At surgery, pericardium was thickened with inflammation of pericardial surface. Very little effusion was present. Pericardial aspiration and window were not done. (Reprinted with permission: Chang S: ECHOCARDIOGRAPHY: TECHNIQUES AND INTERPRETATION. 2nd ed, Lea \& Febiger, Philadelphia, 1981). 


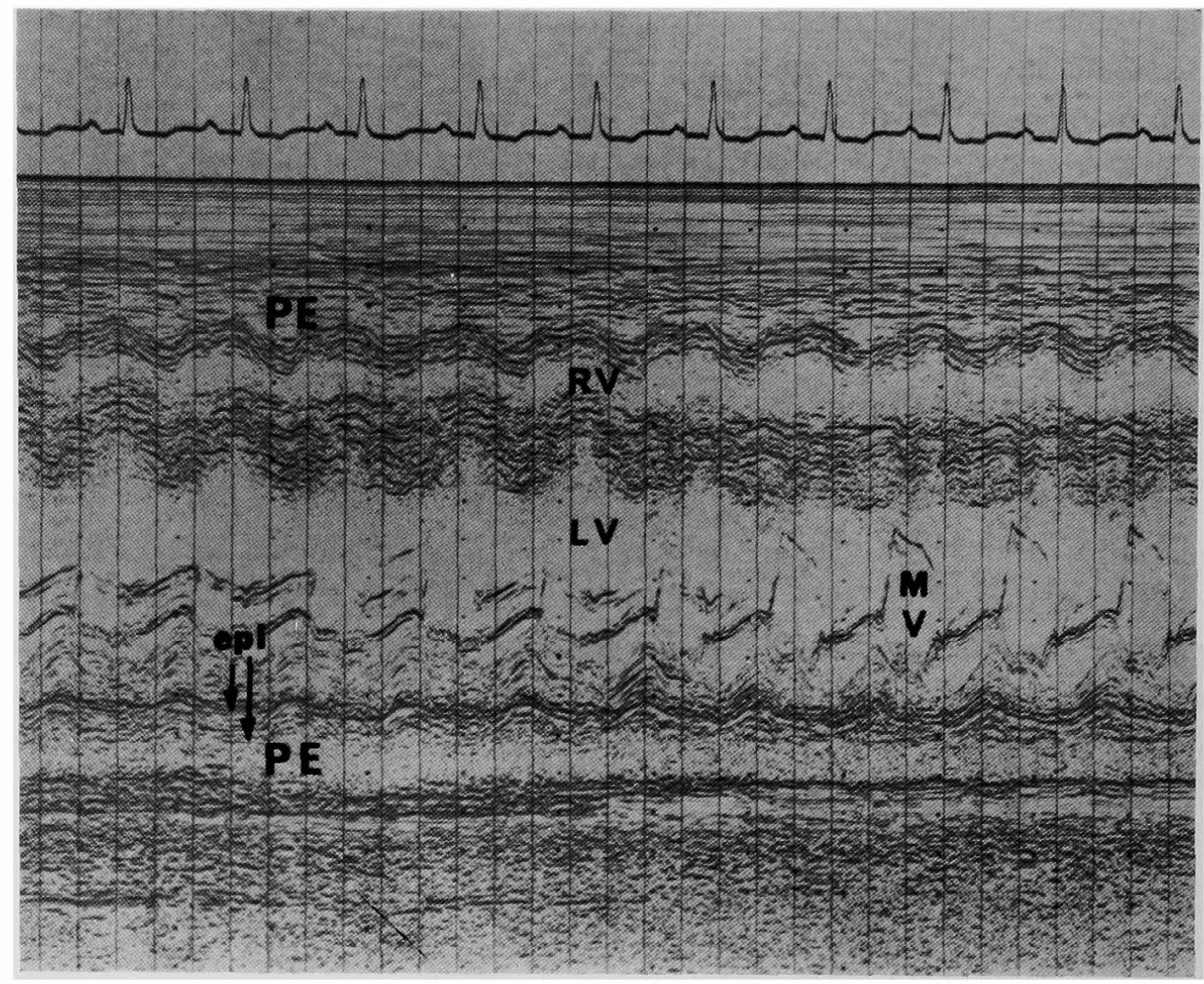

Fig. 7. A 58-year-old male; chronic renal failure, amyloidosis, anemia, hypertension. Echocardiogram showed pericardial effusion (PE) distributed along anterior and posterior cardiac borders. Increased echo-reflectiveness from pericardium and epicardium suggested thickening of these structures. Progressive constrictive pericarditis required surgical removal of thickened parietal pericardium and thickened, constrictive epicardium (epi). RV=right ventricle; $L V=$ left ventricle; $M V=$ mitral valve motion.

suspected effusions were evaluated within the clinical setting and were considered to be hemodynamically insignificant. ${ }^{40)}$ Berger and collegues ${ }^{41)}$ reviewed echographic records on 2,106 patients and found 178 patients $(8.5 \%)$ with pericardial effusion. The effusion was unsuspected in $41 \%$ (70/171). The majority of these patients also had underlying organic heart disease, with and without congestive heart failure.

While quantitation of pericardial fluid volume remained equivocal, evaluation of fluid distribution was much more accurate with application of two-dimensional echocardiographic techniques. ${ }^{29), 361,45)-49 \text { \} }}$ Using a variety of cross-sectional views, one can identify areas of greatest fluid accumulation and monitor total cardiac movement within the fluid. Two-dimensional echocardiography has been ideal to identify areas of compartmentalization within the pericardial fluid. ${ }^{50), 52)}$ Its clinical utility was demonstrated in a 
patient whose early echographic evidence of effusive-adhesive pericardial disease progressed into constrictive pericarditis requiring surgical pericardectomy (Figures 7, 8). ${ }^{52)}$

\section{SUMMART:}

The 26 year history of echocardiographic detection of pericardial effusion ideally demonstrates the scientific method. The initial observations by Edler and Hertz in 1954 lead to animal experiments by Feigenbaum ${ }^{4)}$ and Soulen ${ }^{37)}$ many years later. Human applications were confirmed again and again with cardiac catheterization, surgery, autopsy and radiologic procedures. Older
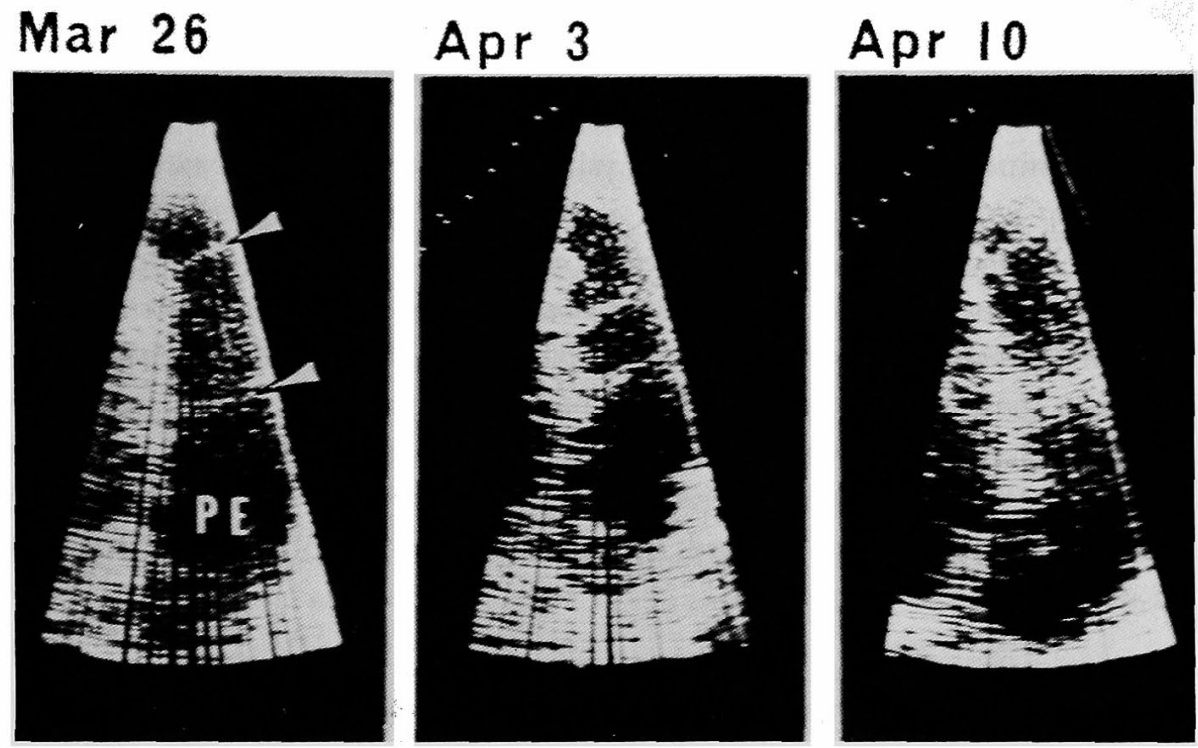

Fig. 8. Two-dimensional, long-axis, apical echocardiograms from same patient whose M-mode echogram appears in Figure 7. (March 26), A large quantity of pericardial effusion with adhesive strands (arrowheads) separated lateral left ventricular wall from pericardium. (April 3), Quantity of pericardial effusion decreased following aspiration of $200 \mathrm{~m} l$ sanguineous fluid. Adhesions were still present and more echo-reflective. (April 10), Individual adhesive strands were poorly differentiated. More echo-reflective material appeared in effusion. Patient developed clinical cardiac tamponade each time hemodialysis was attempted. Patient was referred to surgery for pericardectomy at which time the pericardium was found to be adherent to underlying structures consisting of grumous material and a tough, constrictive epicardium. (Reprinted with permission: Chang S, Chang JK: Progressive constrictive pericarditis. in RECENT ADVANGES IN ULTRASOUND DIAGNOSIS, II. International Congress Series, No. 498. Proceedings of International Symposium on Recent Advances in Ultrasound Diagnosis. Excerpta Medica, Amsterdam, 1980). 
methods of effusion detection were compared to this new and noninvasive method and found lacking. Echocardiography has been a safe, reliable and accurate method to establish the presence of pericardial effusion in the symtomatic and asymtomatic patient. ${ }^{22)}$,23) It has been used as the diagnostic standard for other detection methods. ${ }^{53)-55}$ Investigators and clinicians are now utilizing echocardiography to explain cardiac physiology when pericardial effusion is present; and to follow the effects of their therapeutic interventions. While the presence of pericardial effusion has proven to be more prevalent than expected, the pathologic and hemodynamic significance of unsuspected effusion has not yet been established. Experimental and clinical studies are continuing with the aid of computerized technology for data retrieval and analysis. Thousands of patients are examined yearly with echocardiography and their statistics roll from the pages of scientific and clinical publications. The world's literature is at one's fingertips. But-the echocardiogram and its derived data are only as good as the knowledge and skill of the examiner, technologist and physician alike who ". . . must understand the physics of ultrasound, the operation of a complex electronic instrument, the nature of intracardiac anatomy, and clinical cardiology as well as echographic manifestations of normal and disease conditions. Information can seldom be extracted retrospectively from the echocardiogram that was not deliberately depicted at the time of the examination." 22)

More than a quarter of a century has honed present day skills to record and interpret echocardiographic tracings of pericardial effusion. Yet, it is sobering to consider how primitive our best efforts are compared to methods still unknown which will be used by technologists and physicians fifty years from now.

\section{REFERENCES}

1. Edler I, Hertz CH: The use of ultrasonic reflectoscope for the continuous recording of the movements of heart walls. Kugliga Fysiografiska Sällkapets i Lung förhandlingar. Bd. 24. Nr. 5, March 10, 1954

2. Edler I: The diagnostic use of ultrasound in heart disease. Acta Med Scand 152 (Suppl 308): 32,1955

3. Edler I: Ultrasoundcardiography. Acta Med Scand 170 (Suppl): 1961

4. Feigenbaum H, Waldhausen JA, Hyde LP: Ultrasound diagnosis of pericardial effusion. JAMA 191: 107, 1965

5. Moss $\Lambda J$, Bruhn F: The echocardiogram: an ultrasound technic for the detection of pericardial effusion. N Engl J Med 274: 380, 1966

6. Feigenbaum H, Zaky A, Waldhausen JA: Use of ultrasound in the diagnosis of pericardial effusion. Ann Intern Med 65: 443, 1966

7. Soulen RL, Lapayowker MD, Gimenez J: Echocardiography in the diagnosis of pericardial effusion. Radiology 86: 1047, 1966

8. Goldschlager AW, Freeman LM, Davis PJ: Pericardial effusion and echocardiography. False results with ultrasound reflection method. NY State J Med 7: 1854, 1967 
9. Rothman J, Chase NE, Kricheff II, Mayoral R, Beranbaum ER: Ultrasonic diagnosis of pericardial effusion. Circulation 35: 358, 1967

10. Klein, JJ, Segal BL: Pericardial effusion diagnosed by reflected ultrasound. Am J Cardiol 22: 57,1968

11. Pate JW, Gardner HC, Norman RS: Diagnosis of pericardial effusion by echocardiography. Ann Surg 165: 826, 1967

12. Christensen EE, Bonte $\mathrm{FJ}$ : The relative accuracy of echocardiography, intravenous $\mathrm{CO}_{2}$ studies and blood-pool scanning in detecting pericardial dffusion in dogs. Radiology $91: 265$, 1968

13. Feigenbaum H: Ultrasonic cardiology: Diagnostic ultrasound as an aid to the management of patients with pericardial effusion. Dis Chest 55: 59, 1969

14. Feigenbaum $\mathrm{H}$, Zaky A, Waldhausen JA: Use of reflected ultrasound in detecting pericardial effusion. Am J Cardiol 19: 84, 1967

15. Goldberg BB, Pollack HM: Uitrasonic aspiration transducer. Radiology 102: 187, 1972

16. Goldberg BB, Pollack HM: Ultrasonically guided pericardiocentesis. Am J Cardiol 31: 490,1973

17. Feigenbaum $\mathrm{H}$ : Echocardiographic diagnosis of pericardial effusion. Am J Cardiol 26: 475, 1970

18. Chang S: M-mode echocardiographic techniques and pattern recognition. Lea \& Febiger, Philadelphia, 1976 (Teaching manual, 1969-74 prior to publication)

19. Casarella WJ, Schneider BO: Pitfalls in the ultrasonic diagnosis of pericardial effusion. Radiology 110: 760, 1970

20. Feigenbaum H: Echocardiography. Lea \& Febiger, Philadelphia, 1972

21. Abbasi AS, Ellis N, Flynn JU: Echocardiographic M-scan technique in the diagnosis of pericardial effusion. J Clin Ultrasound 1: 300,1973

22. Ellis K, Latham DL: Pericarditis and pericardial effusion. Radiologic and echocardiographic diagnosis. Radiol Clin N Amer 11: 393, 1973

23. Horowitz MS, Schultz CS, Stinson EB, Harrison DC, Popp RL: Sensitivity and specificity of echocardiographic diagnosis of pericardial effusion. Circulation 50: 239, 1974

24. Felner JM, Fleming WH, Franch RH: Echocardiographic identification of a pericardial cyst. Chest $68: 386,1975$

25. Foote WC, Jefferson CM, Price HL: False positive echocardiographic diagnosis of pericardial effusion. Result of tumor encasement of the heart simulating constrictive pericarditis. Chest $71: 546,1977$

26. Tajik AJ: Echocardiography in pericardial effusion. Am J Cardiol 63: 29, 1977

27. Child JS, Abbasi AS, Pearce ML: Echocardiographic differentiation of mediastinal tumors from primary cardiac disease. Chest 67: 108, 1975

28. Tingelstad JB, McWilliams NB, Thomas CE: Confirmation of a retrosternal mass by echocardiogram. J Clin Ultrasound 4: 129, 1976

29. Matsuo H, Matsumoto M, Hamanaka Y, Ohara T, Senda S, Inoue M, Abe H: Rotational excursion of heart in massive pericardial effusion studied by phased-array echocardiography. Br Heart J 41: 513, 1979

30. Walinsky R: Pitfalls in the diagnosis of pericardial effusion. in Clinical Echocardiography. Kotler MN, Segal BL (eds), F. A. Davis, Philadelphia, p 111-122, 1978

31. Liedtke AJ, DeJoseph RL, Zelis R: Echocardiographic observations in inflammatory pericarditis. Ann Intern Med 84: 573, 1976

32. D'Cruz I, Prabhu R, Cohen HC, Glick G: Potential pitfalls in quantification of pericardial effusions by echocardiography. Br Heart J 39: 529, 1977

33. Feigenbaum H, Zaky A, Grabhorn L: Cardiac motion in patients with pericardial effusion. Circulation 34: 611, 1966

34. LeMire F, Tajik AJ, Giuliani ER, Gau GT, Schattenberg TT: Further echocardiographic observations in pericardial effusion. Mayo Clin Proc 51: 13, 1976

35. Greene DA, Kleid JJ, Naidu S: Unusual echocardiographic manifestation of pericardial 
effusion. Am J Cardiol 39: 112, 1977

36. Martin RP, Rakowski H, French J, Popp RL: Localization of pericardial effusion with wide angle phased array echocardiography. Am J Cardiol 42: 904, 1978

37. Soulen RL, Lapayowker MD, Cortes F: Distribution of pericardial fluid: Dynamic and static influences. Am J Roentgenol 103: 583, 1968

38. Bryk D, Kroop IG, Budow J: The effect of heart size, cardiac tamponade, and phase of the cardiac cycle on the distribution of pericardial fluid. Radiology 93: 273, 1969

39. Gray H: Anatomy of the Human Body. 29th ed, Lea \& Febiger, Philadelphia, p 542, 1973

40. Riba AL, Morganroth J: Unsuspected substantial pericardial effusions detected by echocardiography. JAMA 236: 2623, 1976

41. Berger M, Bobak L, Jelveh M, Goldberg E: Pericardial effusion diagnosed by echocardiography. Chest 74: 174, 1978

42. Prakash R, Moorthy K, Del Vicario M, Aronow WS: Reliability of echocardiography in quantitating pericardial effusion: A prospective study. J Clin Ultrasound 5: 398, 1977

43. Vignola PA, Pohost GM, Curfman GD, Myers GS: Correlation of echocardiographic and clinical findings in patients with pericardial effusion. Am J Cardiol 37: 701, 1976

44. Gabor G, Winberg F, Bloom H: Electrical and mechanical alteration in pericardial effusion. Chest 59: 341, 1971

45. Zoneraich $\mathrm{S}$, Zoneraich $\mathrm{O}$, Rhee JJ: New poorly recognized echocardiographic findings: Occurrence in patients with pericardial effusion. JAMA 236: 1954, 1976

46. Friedman MJ, Sahn DJ, Haber K: Two-dimensional echocardiography and B-mode ultrasonography for the diagnosis of loculated pericardial effusion. Circulation 60: 1644, 1979

47. Martin RP, Bowden R, Filly K, Popp RL: Intrapericardial abnormalities in patients with pericardial effusion: Findings by two-dimensional echocardiography. Circulation 61: 568, 1980

48. Haaz WS, Mintz GS, Kotler MN, Parry WR, Segal BL: Two-dimensional echocardiographic recognition of the descending thoracic aorta: Value in differentiating pericardial from pleural effusions. Am J Cardiol 46: 739, 1980

49. Ikäheimo M, Tkhaunen J: Postpericardiotomy syndrome diagnosed by echocardiography. Scand J Thorac Cardiovasc Surg 13: 305, 1979

50. Chiaramida SA, Goldman MA, Zema MJ, Pizzarello RA, Goldberg HM: Echocardiographic identification of intrapericardial fibrous strands in acute pericarditis with pericardial effusion. Chest 77: 85, 1980

51. Chang S: Echocardiography: Techniques and Interpretation, 2nd ed, Lea \& Febiger, Philadelphia, 1981

52. Chang S, Chang JK: Progressive constrictive pericarditis. in Recent advances in ultrasound diagnosis, II. International Congress Series, No. 498. Proceedings of International Symposium on Recent Advances in Ultrasound Diagnosis. Excerpta Medica, Amsterdam, 1980

53. Manyari DE, Milliken JA, Colwell BT, Burggraf GW: Detection of pericardial effusion by chest roentgenography and electrocardiography versus echocardiography. Canad MA J 119: 445,1978

54. Sbarbaro JA, Brooks HL: Pericardial effusion and electrical alternans. Postgrad Med 63 : 105,1978

55. Salem BI, Schnee M, Leatherman LL, de Castro CM, Benrey J: Electrocardiographic pseudoinfarction pattern: Appearance with a large posterior pericardial effusion after cardiac surgery. Am J Cardiol 42: 681, 1978 